\title{
Primary Large-Cell Neuroendocrine Carcinoma of the Breast Occurring in a Pre-Menopausal Woman
}

\author{
Noriko Yoshimura $^{a}$ Tatsunari Sasada $^{a}$ Shuji Yonehara ${ }^{b}$ \\ a Department of Surgery, Onomichi General Hospital, Hiroshima, Japan; \\ ${ }^{\mathrm{b}}$ Department of Pathology, Onomichi General Hospital, Hiroshima, Japan
}

\section{Established Facts}

- Primary LCNEC of the breast is a rare malignancy, and its biological behavior remains unknown.

- Occurrences of primary LCNEC of the breast in pre-menopausal women are extremely rare.

\section{Novel Insights}

- Our case of LCNEC-breast, which occurred in a 34-year-old woman, represents LCNEC-breast of the youngest woman so far reported in the English literature.

\section{Keywords}

Breast cancer - Large cell neuroendocrine carcinoma . Neuroendocrine tumor

\section{Summary}

Background: Primary large-cell neuroendocrine carcinoma of the breast (LCNEC-breast) in pre-menopausal women is extremely rare. Case report: A 34-year-old woman presented with a mass in the left breast that was diagnosed as neuroendocrine carcinoma by needle biopsy. Computed tomography revealed no lymph node swelling or distant organ metastasis. Left mastectomy and sentinel lymph node biopsy were performed and metastasis to the axial lymph node was detected. Left axillary lymph node dissection was performed and histopathological and immunohistochemical examination revealed that the tumor was an LCNEC-breast, which was $6.0 \mathrm{~cm}$ in size and positive for the neuroendocrine markers (neuron-specific enolase, chromogranin A, and synaptophysin). The tumor cells were hormone-receptor positive and HER2 negative. The patient refused any ad- juvant hormonal therapy, chemotherapy or radiotherapy. She has been followed up for 4 years without medication, and no recurrence has been noted. Conclusion: We present a case of LCNEC-breast in a 34-year-old woman. Our case represents the youngest woman with LCNEC-breast reported in the English literature.

\section{Introduction}

Neuroendocrine carcinoma (NEC) is a distinct malignant tumor that shows evidence of neuroendocrine differentiation and most commonly occurs in the lung and gastrointestinal tract. Large-cell NEC (LCNEC) accounts for less than 1-5\% of all neuroendocrine tumors throughout the body and less than $0.1 \%$ of all breast cancers [1-3]. In this report, we present a case of LCNECbreast occurred in a 34-year-old pre-menopausal woman.

\section{KARGER \\ Fax +497614520714

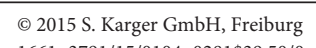




\section{Case report}

A 34-year-old woman presented with a palpable mass in her left breast. Her past medical history was not remarkable. She had no previous breast disease or family history of breast cancer. Her physical examination revealed a non-fixed hard mass at the upper outer region of the left breast. Mammography demonstrated an asymmetric, microlobulated, hyperdense mass in the upper external quadrant of the left breast. Microcalcification were absent. Computed tomography (CT) examination revealed a highly contrasted mass (fig. 1a), but no swelling of axial lymph nodes or abnormal findings were observed in distant organs. Breast magnetic resonance imaging (MRI) revealed a contrasted mass without intraductal progression in her left breast (fig. 1b). She underwent left breast mastectomy and sentinel lymph node biopsy. The sentinel lymph node was metastatic and left axillary lymph node dissection was performed. Histological examination showed proliferation of the tumor cell with the large bare nuclei. Immunohistochemical examination showed that more than $50 \%$ of the tumor cells were positive for neuroendocrine markers (neuron-specific enolase (NSE), chromogranin A, synaptophysin), which is consistent with LCNEC-breast (fig. 2).The nuclear grade of the tumor cell was 3 . The tumor was composed predominantly of an invasive lesion component and partly of an in situ component. The tumor cells were hormone-receptor positive and HER2 negative. The Ki-67 labeling index was 25\%. Lymph node metastases were found in 5 of 16 dissected lymph nodes. The patient refused any adjuvant therapy, including chemotherapy with taxane or anthracycline, hormonal therapy, and radiotherapy. There were no signs of recurrence 4 years after surgery.

\section{Discussion}

Breast cancers are now categorized by histological and immunochemical subtypes and biological features; the efficacy of medications and the patient prognosis are examined for each subtype. However, NEC, particularly LCNEC-breast, remains poorly understood. In the 2012 edition of the WHO classification, 3 distinct subtypes were described: well-differentiated neuroendocrine tumors, poorly differentiated NEC or small cell carcinoma, and invasive breast carcinoma with neuroendocrine differentiation. Subsequently, LCNEC and carcinoid have been described as other rare histological subtypes [3]. More than $97 \%$ of NECs occur in the gastrointestinal tract and respiratory system where endocrine cells consistently found among the exocrine cells. In addition to NECs, primary malignant breast tumors that can develop in multiple organs include malignant lymphoma [4], clear cell carcinoma [5],
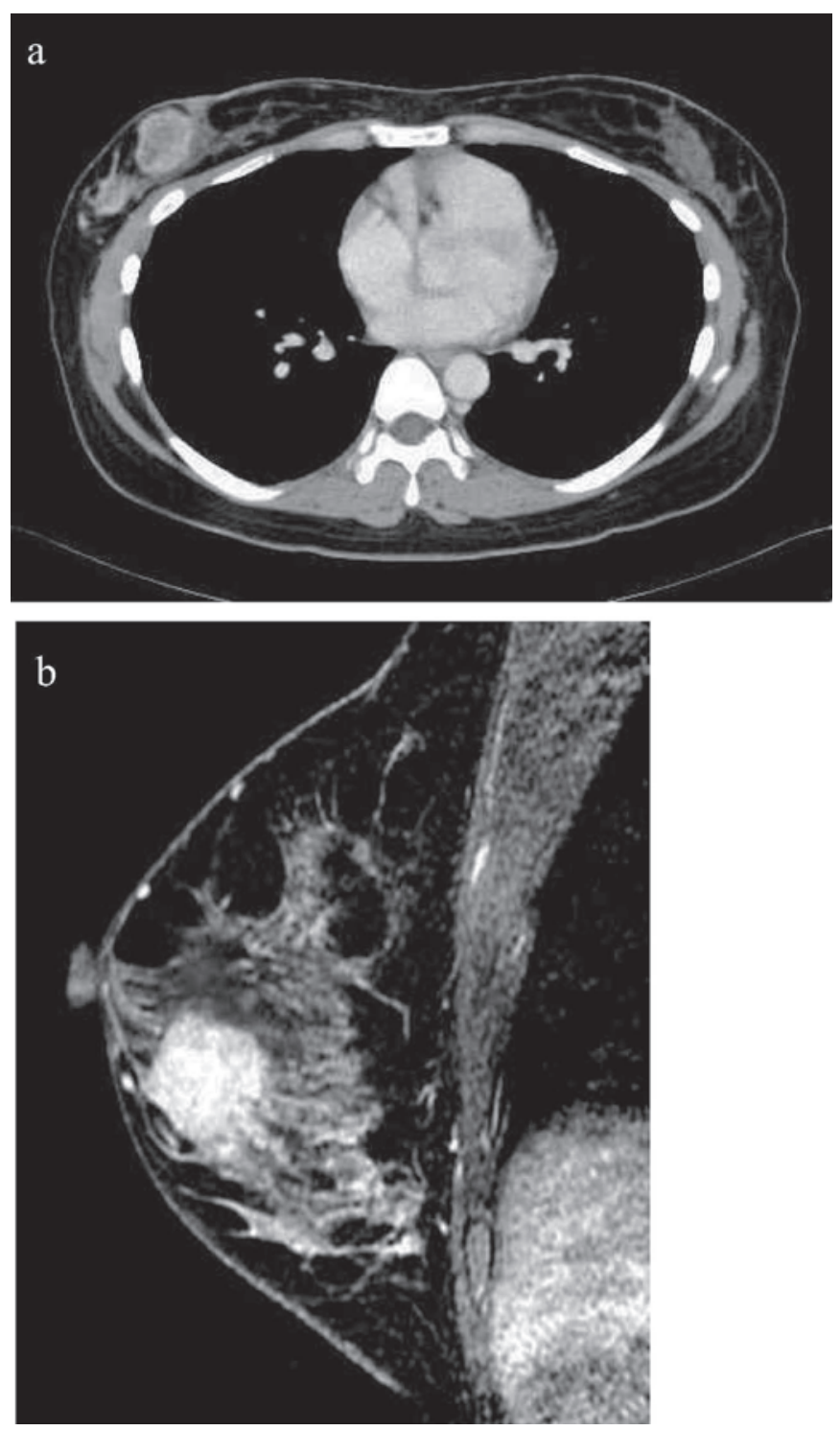

Fig. 1. Enhanced CT scan and MRI. a CT scan reveals a well-defined, highly enhancing mass in the right breast. b MRI reveals enhanced tumor.
Fig. 2. Pathological findings. The tumor is composed of solid nests and trabeculae without tubule formation. Large and polygonal shaped cells with faintly granular cytoplasm are separated by dense collagen palisading. The nuclear atypia of tumor cells is low. A, B low-power field, C high-power field (hematoxylin and eosin stain). D-F Tumor cells are positive for neuroendocrine markers. chromogranin A (D), neuron-specific enolase $(\mathbf{E})$, and synaptophysin $(\mathbf{F})$.

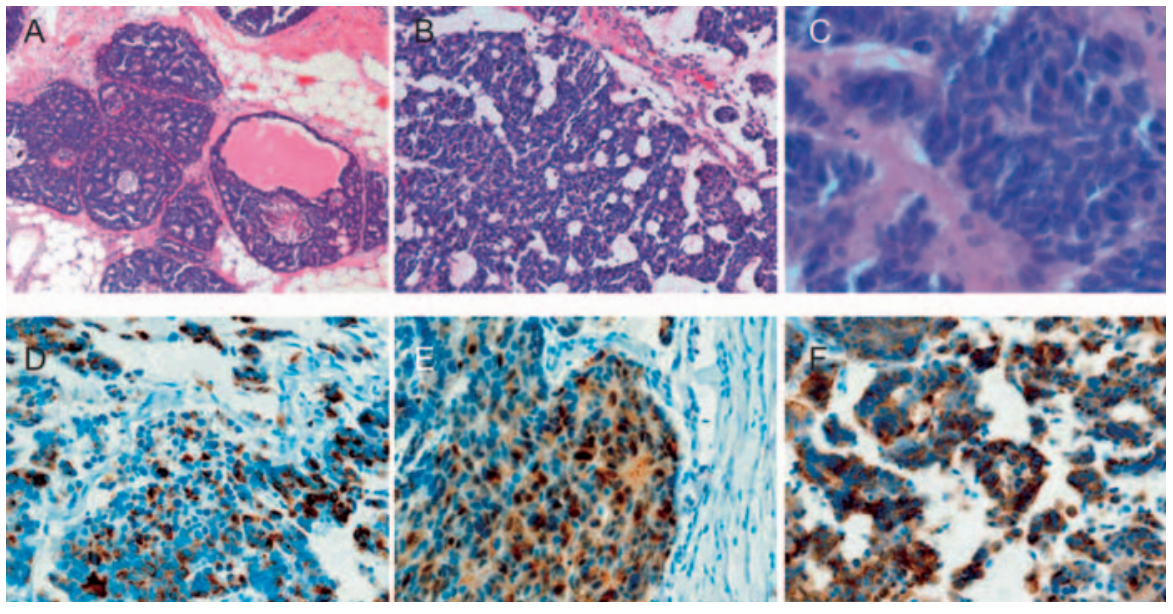


and sarcoma [6]. Therefore, it is important to exclude the possibility that the tumor is the result of metastasis from another organ. In our case, there were no lesions in the lung or abdominal organs on CT examination. If metastases from other organs are suspected, positron emission tomography-CT and gastroenterological endoscopy should also be considered.

Sapino et al. [7] commented that benign neoplastic neuroendocrine lesions of the breast have not been described, and that all neuroendocrine lesions in the breast are considered to be carcinomas. In 2012, Alkaied et al. [8] presented a detailed review of all previous literature about primary NEC. No neuroendocrine cells have been detected in normal human mammary cells studied by immunohistochemistry or electron microscopy [9]. There are some hypotheses about the origin of LCNEC-breast; however, the definitive biological significance is unclear. These tumors are distinct from 'breast carcinomas with neuroendocrine differentiation' [7]. The histopathological features of LCNEC are large cell size, polygonal shape, low nuclear-cytoplasmic ratio, finely granular eosinophilic cytoplasm, occasionally prominent nucleoli, peripheral palisading, mitosis, and necrosis. More than $90 \%$ of NEC of the LCNEC-breast appear to be estrogen receptor/progesterone receptor positive, and HER2 negative. The immunohistochemical definition is that more than $50 \%$ of the tumor cells are positive for neuroendocrine markers (NSE, chromogranin A, synaptophysin) [2, 7, 10-13].

Another notable point about our patient was her age; she was diagnosed and treated for LCNEC-breast as a pre-menopausal woman in her 30s. Some authors suggest that NEC is usually seen in elderly women. It tends to occur in women who are post-menopausal $[8,11,12,14,15]$. Upalakarin et al. [16] reported that the average age at diagnosis of neuroendocrine breast cancer is 10 years later than the usual types of breast cancer. A search of PubMed did not reveal any other case reports of LCNEC of the breast occurring in women in their 30s.
The first-line treatment of primary LCNEC is considered to be surgery [15]. The prognosis of this rare disease remains controversial. LCNEC shows limited responsiveness to drug treatment, and there have been reports that LCNEC has a poor prognosis when compared to other types of breast cancer [8]. In recent literature, however, non-small-cell type NEC have been shown, with adequate surgery and medication, to have a relatively good prognosis $[15$, 17]. Because NEC is rare, and there is an absence of randomized controlled trials, there is no consensus on the optimal treatment. It is performed according to other types of invasive carcinoma, including anthracyclin and taxane, but it is unclear if these are appropriate for NEC. Phase II studies for LCNEC in the lung have been performed using existing lung cancer treatment drugs such as cisplatin, etoposide, lirinotecan $[18,19]$. In the pancreas or lung, genetic studies on NEC have advanced greatly, and some molecular-target agents are expected to become a future therapeutic approach [20]. In addition, Iyoda et al. [21] discussed specific genes or markers for LCNEC that can lead to a more responsive chemotherapy. Collaboration with doctors who specialize in NEC treatment would be valuable in seeking a medical therapy based on established evidence. The limitation of our case is the short follow-up term and that the recommended adjuvant therapy was not adopted.

In summary, we report a case of LCNEC-breast occurring in a 34-year-old pre-menopausal woman. Our case represents LCNECbreast of the youngest woman so far mentioned in the English literature and may demonstrate 1 aspect of the biological features of LCNEC-breast. Further investigations are needed to establish the optimal management of this unusual tumor.

\section{Disclosure Statement}

There is no conflict of interest to declare.

\section{References}

1 Maluf HM, Koerner FC: Carcinomas of the breast with endocrine differentiation: A review. Virchows Arch 1994;425:449-457.

2 Papotti M, Macri L, Finzi G, et al.: Neuroendocrine differentiation in carcinomas of the breast: A study of 51 cases. Semin Diagn Pathol 1989;6:174-188.

3 Lakhani S, Ellis I, Schnitt S, et al.: World Health Organisation classification of tumors of the breast, 4 th ed. Lyon, France, IARC Press, 2012.

4 Avenia N, Sanguinetti A, Cirocchi R, et al.: Primary breast lymphomas: A multicentric experience. World J Surg Oncol 2010;8:53.

5 Dina R, Eusebi V: Clear cell tumors of the breast. Semin Diagn Pathol 1997;14:175-182.

6 Lahat G, Lev D, Gerstenhaber F, et al.: Sarcomas of the breast. Expert Rev Anticancer Ther 2012;12:1045-1051.

7 Sapino A, Righi L, Cassoni P, et al.: Expression of the neuroendocrine phenotype in carcinomas of the breast. Semin Diagn Pathol 2000;17:127-137.

8 Alkaied H, Harris K, Azab B, Dai Q: Primary neuroendocrine breast cancer, how much do we know so far? Med Oncol 2012;29:2613-2618.
Viacava P, Naccarato AG, Nardini V, Bevilacqua G: Breast carcinoma with osteoclast-like giant cells: Immunohistochemical and ultrastructural study of a case and review of the literature. Tumori 1995;81:135-141.

10 Bocker W: [WHO classification of breast tumors and tumors of the female genital organs: Pathology and genetics]. Verh Dtsch Ges Pathol 2002;86:116-119.

11 Hanna MY, Leung E, Rogers C, Pilgrim S: Primary large-cell neuroendocrine tumor of the breast. Breast J 2013;19:204-206.

12 Kim JW, Woo OH, Cho KR, et al.: Primary large cell neuroendocrine carcinoma of the breast: Radiologic and pathologic findings. J Korean Med Scie 2008;23: 1118-1120.

13 Okoshi K, Saiga T, Hisamori S, et al.: A case of cytokeratin 20-positive large-cell neuroendocrine carcinoma of the breast. Breast Cancer 2012;19:360-364.

14 Yerushalmi R, Hayes MM, Gelmon KA: Breast carcinoma-rare types: Review of the literature. Ann Oncol 2009;20:1763-1770.

15 Berruti A, Saini A, Leonardo E, et al.: Management of neuroendocrine differentiated breast carcinoma. Breast 2004;13:527-529.
16 Upalakalin JN, Collins LC, Tawa N, Parangi S: Carcinoid tumors in the breast. Am J Surg 2006;191:799805.

17 Tsai WC, Yu JC, Lin CK, Hsieh CT: Primary alveolartype large cell neuroendocrine carcinoma of the breast. Breast J 2005; 11:487

18 Le Treut J, Sault MC, Lena H, et al.: Multicentre phase II study of cisplatin-etoposide chemotherapy for advanced large-cell neuroendocrine lung carcinoma: The GFPC 0302 study. Ann Oncol 2013;24:1548-1552.

19 Niho S, Kenmotsu H, Sekine I, et al.: Combination chemotherapy with irinotecan and cisplatin for largecell neuroendocrine carcinoma of the lung: A multicenter phase II study. J Thorac Oncol 2013;8:980-984.

20 Oberg K, Casanovas O, Castano JP, et al.: Molecular pathogenesis of neuroendocrine tumors: Implications for current and future therapeutic approaches. Clin Cancer Res 2013;19:2842-2849.

21 Iyoda A, Hiroshima K, Nakatani Y, Fujisawa T: Pulmonary large cell neuroendocrine carcinoma: Its place in the spectrum of pulmonary carcinoma. Ann Thorac Surg 2007;84:702-707. 